\title{
Workplace Violence in the Health Care Facility
}

\author{
Kaleab Tesfaye Tegegne ${ }^{1 *}$, Andualem Zenebe ${ }^{1}$, Abiyu Ayalew Assefa ${ }^{1}$, Eleni Tesfaye Tegegne $^{2}$, \\ Mekibib Kassa Tessema ${ }^{3}$ and Wosenyeleh Semeon Bagajjo ${ }^{4}$ \\ ${ }^{1}$ Department of Public Health, Hawassa College of Health Science, Ethiopia \\ ${ }^{2}$ College of Medicine and Health Science, School of Nursing, University of Gondar, Ethiopia \\ ${ }^{3}$ Leishmania Research and Treatment Center, University of Gondar, Ethiopia \\ ${ }^{4}$ Dean of Hawassa College of Health Science, Ethiopia
}

*Corresponding author: Kaleab Tesfaye Tegegne, Department of Public Health, Hawassa College of Health Science, Hawassa, Ethiopia

\begin{tabular}{|c|c|}
\hline ARTICLE INFO & ABSTRACT \\
\hline Received: May 24, 2021 & Citation: Kaleab Tesfaye T, Andualem Z, Abiyu Ayalew A, Eleni Tesfaye T, Mekibib Kassa \\
\hline Published: 慧 June 04, 2021 & $\begin{array}{l}\text { T, Wosenyeleh Semeon B. Workplace Violence in the Health Care Facility. Biomed J Sci \& } \\
\text { Tech Res 36(2)-2021. BISTR. MS.ID.005826. }\end{array}$ \\
\hline
\end{tabular}

\section{Introduction}

In the world different countries the workplace violence definition varies in different socio-political contexts. The difficult thing for the analysis is the inexistence of similar definition of workplace violence. In terms of both the scope and consequences of workplace violence, a broad rather than a restrictive definition is needed, the definition of WHO "The intentional use of power, threatened or actual, against another person or against a group, in work-related circumstances, that either results in or has a high degree of likelihood of resulting in injury [1].

\section{A Conceptual Model}

The existing literatures for conceptual models on workplace violence include three levels of factors - individual, organizational, and societal [2-6].

\section{Individual Factors}

Worker Characteristics: Previous studies reported that Males have increased risk of workplace violence [7] and most victims were practical nurses with special training in mental health or psychiatry [8].

Perpetrator Characteristics: The factors include demographic (male sex, age under 45 years, low socio-economic status, low level of education, non-white race [9], psychological and/or behavioural disorders [10] and personality factors (e.g., negative affectivity, Type A behaviour, hostile attribution style, locus of control [2].

\section{Interaction Factors}

It reflects the tendency to interpret the actions of others in a negative or threatening manner. This variable is likely important to both workers and perpetrators as they attempt to interpret the actions of the other; misattributions of intent could lead to confrontation.

\section{Organizational Factors}

"Increase temperature, humidity, cold, poor illumination and quality of air, noise, and overcrowding all associated with increased human aggression" [5]. Safety personnel are important - particularly -trained personnel - as a deterrent. The nurses also believed that understaffing placed them at increased risk for violence, partly because it increased patient wait times, and partly because it left them alone with patients [11]. Low work group harmony, low supervisor support, a late-night work schedule, and having professional status were associated with increased risk for having been personally threatened at work [12]. Increasing diversity within the workplace, employee monitoring, change in management, pay cuts or freezes, and use of part-time help were all associated with having experienced aggression in the workplace [13]. 


\section{Community/Neighbourhood Factors}

Community factors such as the level of violent crime, illegal drug use, and gang activity can affect both the types of patients that are treated and the problems that they present [11]. Community factors such as poverty and minority cultures have strong relationships with health-care facilities that are staffed by largely majority cultures. Shortage of resources in the community may influence the quality of care received due to inability of the health-care system to provide efficient service for those in need of health service. This, in turn, may increase levels of distrust and suspicion [11].

\section{Societal Factors}

Some of the factors that have been noted include increased workplace diversity $[6.11,14]$, changing norms surrounding the acceptance of aggression [5,10] downsizing, global competition, and constantly changing technology [14] and financial stress associated with not having the means to maintain a chosen lifestyle, shifting family structures, and social isolation [10]. Currently many quantitative research methods have done on the field of violence research. We recommend researchers who have interest on workplace violence to undertake Qualitative research methods and this will increase our understanding of the various forms of workplace violence and will help to know how perceptions of violence and their antecedents may vary between individuals. The other Research gap is the impacts of workplace violence especially on a victim's personal life and financial situation, coping strategies, costs of absenteeism/time away from work, etc. should be studied.

\section{References}

1. WHO (1995) Violence: a public health priority. Geneva: World Health Organization.

2. Beugre CD (1998) Understanding organizational insider-perpetuated workplace aggression: An integrative model. In: SB Bacharach, PA Bamberger \& WJ Sonnenstuhl (Eds.), Research in the Sociology of organizations. Deviance in and of organizations, Stamford CT: JAI Press, Inc, (pp: 163-196).

3. Folger R, Baron RA (1996) Violence and hostility at work: A model of reactions to perceived injustice. In: GR VandenBos and EQ Bulatao (Eds.), Violence on the Job. Washington, DC: American Psychological Association pp. 51-85.

4. Levin PF, Hewitt JB, Misner ST (1998) Insights of nurses about assault in hospital-based emergency departments. Image: Journal of Nursing Scholarship 30(3): 249-254.

5. Neuman JH, Baron RA (1998) Workplace violence and workplace aggression: Evidence concerning specific forms, potential causes, and preferred targets. Journal of Management 24(3): 391- 419.

6. Paul RJ, Townsend JB (1998) Violence in the workplace - a review with recommendations. Employee Responsibilities and Rights Journal 11: $1-13$.

7. Schulte JM, Nolt BJ, Williams RL, Spinks CL, Hellsten JJ, et al. (1998) Violence and threats of violence experienced by public health field workers. American Journal of Public Health 280(5): 439-442.

8. Arnetz JE (1998) The Violent Incident Form (VIF): A practical instrument for the registration of violent incidents in the health care workplace. Work \& Stress 12(1): 17-28.

9. Mossman D (1995) Violence prediction, workplace violence, and the mental health expert.Consulting Psychology Journal: Practice and Research 47(4): 223-233.

10. Kelleher MD (1997) Profiling the lethal employee. Westport, CT: Praeger.

11. Levin PF, Hewitt JB, Misner ST (1998) Insights of nurses about assault in hospital-based emergency departments. Image: Journal of Nursing Scholarship 30(3): 249-254.

12. Cole LL, Grubb PL, Sauter SL, Swanson NG, Lawless P, et al. (1997) Psychosocial correlates of harassment, threats and fear of violence in the workplace. Scandinavian Journal of Work Environment and Health 23(6): 450-457.

13. Baron RA, Neuman JH (1996) Workplace violence and workplace aggression: Evidence on their relative frequency and potential causes. Aggressive Behavior 22(3): 161-173.

14. McClure LF (1999) Origins and incidence of workplace violence in North America. In: TP Gullotta and SJ McElhaney (Eds.), Violence in homes and communities: Prevention, intervention, and treatment. Thousand Oaks, CA: Sage Publications pp: 71-99.

\section{ISSN: 2574-1241}

DOI: $10.26717 /$ BJSTR.2021.36.005826

Kaleab Tesfaye Tegegne. Biomed J Sci \& Tech Res

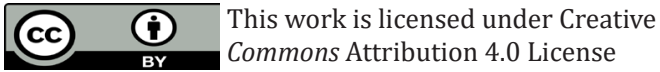

Submission Link: https://biomedres.us/submit-manuscript.php

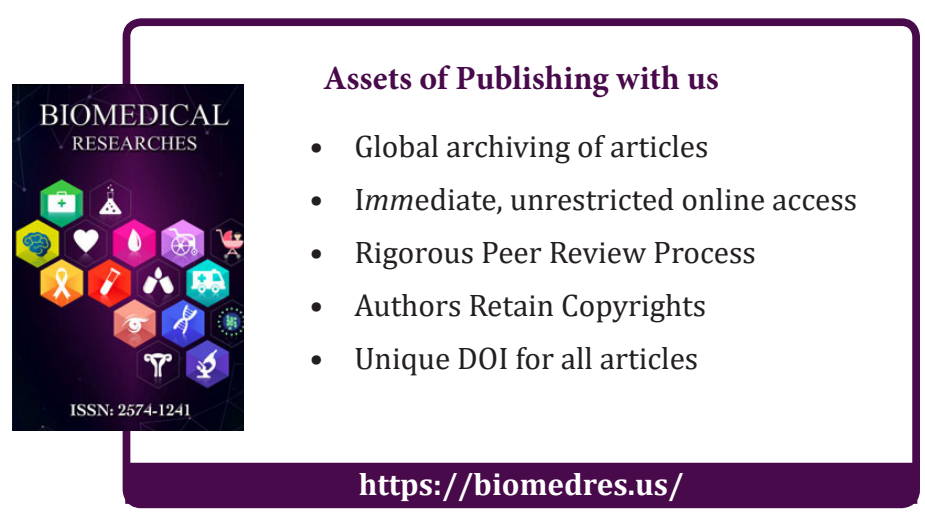

